\title{
Quality assessment of Landsat surface reflectance products using MODIS data
}

\author{
Min Feng ${ }^{a, b, *}$, Chengquan Huang ${ }^{b}$, Saurabh Channan ${ }^{b}$, Eric F. Vermote ${ }^{c}$, Jeffrey G. Masek ${ }^{d}$, \\ John R. Townshend ${ }^{\mathrm{b}}$ \\ a State Key Laboratory of Resources and Environment Information System, Institute of Geographic Sciences and Natural Resources Research, Chinese Academy of Sciences, \\ Beijing 100101, China \\ ${ }^{\mathrm{b}}$ Global Land Cover Facility, Department of Geography, University of Maryland, College Park, MD 20742, USA

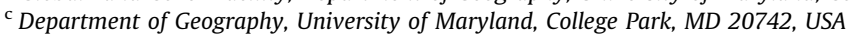 \\ ${ }^{\mathrm{d}}$ Biospheric Sciences Branch, NASA Goddard Space Flight Center, Greenbelt, MD 20771, USA
}

\section{A R T I C L E I N F O}

\section{Article history:}

Received 5 March 2010

Received in revised form

21 February 2011

Accepted 12 April 2011

Available online 30 May 2011

Keywords:

Surface reflectance

Landsat

MODIS

Object-oriented programming

Quality assessment

\begin{abstract}
A B S T R A C T
Surface reflectance adjusted for atmospheric effects is a primary input for land cover change detection and for developing many higher level surface geophysical parameters. With the development of automated atmospheric correction algorithms, it is now feasible to produce large quantities of surface reflectance products using Landsat images. Validation of these products requires in situ measurements, which either do not exist or are difficult to obtain for most Landsat images. The surface reflectance products derived using data acquired by the Moderate Resolution Imaging Spectroradiometer (MODIS), however, have been validated more comprehensively. Because the MODIS on the Terra platform and the Landsat 7 are only half an hour apart following the same orbit, and each of the 6 Landsat spectral bands overlaps with a MODIS band, good agreements between MODIS and Landsat surface reflectance values can be considered indicators of the reliability of the Landsat products, while disagreements may suggest potential quality problems that need to be further investigated. Here we develop a system called Landsat-MODIS Consistency Checking System (LMCCS). This system automatically matches Landsat data with MODIS observations acquired on the same date over the same locations and uses them to calculate a set of agreement metrics. To maximize its portability, Java and open-source libraries were used in developing this system, and object-oriented programming (OOP) principles were followed to make it more flexible for future expansion. As a highly automated system designed to run as a standalone package or as a component of other Landsat data processing systems, this system can be used to assess the quality of essentially every Landsat surface reflectance image where spatially and temporally matching MODIS data are available. The effectiveness of this system was demonstrated using it to assess preliminary surface reflectance products derived using the Global Land Survey (GLS) Landsat images for the 2000 epoch. As surface reflectance likely will be a standard product for future Landsat missions, the approach developed in this study can be adapted as an operational quality assessment system for those missions.
\end{abstract}

(c) 2011 Elsevier Ltd. All rights reserved.

\section{Introduction}

Surface reflectance is the most basic remotely sensed earth surface parameter in the solar reflective wavelengths (Vermote et al., 2006). It provides a primary input for retrieving essentially most higher level surface geophysical parameters, including vegetation indices (Huete et al., 2002), albedo (Fang et al., 2007), leaf area index (Myneni et al., 1997), and photosynthetically active radiation (PAR) (Liang et al., 2006, 2007). While both raw digital

\footnotetext{
* Corresponding author at: State Key Laboratory of Resources and Environment Information System, Institute of Geographic Sciences and Natural Resources Research, Chinese Academy of Sciences, Beijing 100101, China.

E-mail address: feng.tank@gmail.com (M. Feng).
}

numbers (DN) and calibrated top-of-atmospheric (TOA) reflectance have been widely used in land cover mapping and change detection, use of surface reflectance can improve the results from such analysis (Song et al., 2001).

With the launch of the first Landsat in 1972, a series of Landsat satellites have produced large quantities of images useful for land cover and change studies and other earth science applications (Townshend et al., 1991; Goward and Williams, 1997; Goward et al., 2006; Huang et al., 2009a,b). Despite this near 40-year history of the Landsat missions, however, standard Landsat imagery products have been provided in DN or higher level products (e.g., TOA (Roy et al., 2010)), not surface reflectance. This is due in part to many challenges to performing atmospheric correction operationally on Landsat images. Recently, the 
atmospheric correction algorithm developed for the Moderate Resolution Spectroradiometer (MODIS) (Vermote et al., 2002) was adopted for use with Landsat data, and was implemented as part of the Landsat Ecosystem Disturbance Adaptive Processing System (LEDAPS) developed at NASA Goddard Space Flight Center (GSFC) (Masek et al., 2006). As an adaptation of the MODIS Adaptive Processing System (MODAPS) (Justice et al., 2002) for processing Landsat data, the LEDAPS allows rapid processing of large quantities of Landsat images to produce surface reflectance products from the raw radiometry. It has been used to produce a surface reflectance record consisting of over 2000 Landsat images over North America (Masek et al., 2006). After expanding its computing and storage capacity, this system is being adopted for creating global land surface reflectance products using Landsat images assembled through the joint National Aeronautics and Space Administration (NASA)-U.S. Geological Survey (USGS) Global Land Survey (GLS) program, which provide wall-to-wall, orthorectified Landsat coverage of Earth's land area for four epochs centered around 1975, 1990, 2000, and 2005 (Gutman et al., 2008). The LEDAPS atmospheric correction algorithm has also been adopted by other research groups that have needs for processing large quantities of Landsat images, and is being considered a candidate algorithm for producing surface reflectance products for the next Landsat system, the Landsat Data Continuity Mission (LDCM) (Irons and Masek, 2006).

The usefulness of a data product depends to a large degree on its quality and accuracy. Knowledge of the uncertainties of a product is required in order to understand the impact of such uncertainties on downstream applications. While some surface reflectance products derived from Landsat Thematic Mapper (TM) and Enhanced Thematic Mapper Plus (ETM+) images have been validated using ground observations (Vermote et al., 1997a; Liang et al., 2002; Masek et al., 2006; Ouaidrari and Vermote, 1999), the applicability of this ground-based validation approach is constrained by the availability of ground observations, including measurements from AERONET sites (Wang et al., 2009). For large area applications using Landsat images, the required images are typically acquired in dates that most likely differ by months, seasons, or even years. As a result, even when ground observations are available for validating the reflectance value of some of those images, the conclusions reached may not be applicable to other images. In addition to comparison with ground observations, the quality of a product can also be assessed with respect to their intended performance by comparison with other existing products (Roy et al., 2002). Since MODIS surface reflectance products have been validated comprehensively (Vermote et al., 2002; Liang et al., 2002; Fang et al., 2004; Kotchenova and Vermote, 2007; Vermote and Kotchenova, 2008a), they may be used as a reference to assess the quality of Landsat surface reflectance products. The MODIS on the Terra platform follows the same orbit as the Landsat 7. It crosses the equator at about 10:30 AM local solar time, roughly 30 min later than the Landsat 7 (Vermote and Kotchenova, 2008b). For each of the 6 Landsat multispectral bands, there is a MODIS band with a spectral range well within that of the corresponding Landsat band (Landsat 7 Science Data Users Handbook, 2009) (see Table 1). Comparisons between MODIS and Landsat surface reflectance products were performed for limited sites in previous studies, which revealed that the differences in bandwidth between the two instruments only resulted in tolerable differences in reflectance values (Vermote et al., 2002; Masek et al., 2006). The moderate resolution MODIS data are coarser than the $30 \mathrm{~m}$ resolution Landsat data, but they provide global, near-daily repeat coverage, compared to the 16-day repeat cycle of Landsat 7 . In addition, MODIS Terra data products have been made available globally since 2000; they allow quality assessment (QA) of essentially all
Table 1

The 6 multispectral bands of the Landsat 7 and the corresponding MODIS bands.

\begin{tabular}{llll}
\hline $\begin{array}{l}\text { Landsat ETM }+ \\
\text { band }\end{array}$ & $\begin{array}{l}\text { ETM+ bandwidth } \\
(\mathbf{n m})\end{array}$ & $\begin{array}{l}\text { MODIS } \\
\text { band }\end{array}$ & $\begin{array}{l}\text { MODIS bandwidth } \\
(\mathbf{n m})\end{array}$ \\
\hline $\mathbf{1}$ & $450-520$ & 3 & $459-479$ \\
$\mathbf{2}$ & $530-610$ & 4 & $545-565$ \\
$\mathbf{3}$ & $630-690$ & 1 & $620-670$ \\
$\mathbf{4}$ & $780-900$ & 2 & $841-876$ \\
$\mathbf{5}$ & $1550-1750$ & 6 & $1628-1652$ \\
$\mathbf{7}$ & $2090-2350$ & 7 & $2105-2155$ \\
\hline
\end{tabular}

surface reflectance products that could be produced using Landsat 7 images acquired since 2000.

The purpose of this paper is to develop a Landsat-MODIS Consistency Checking System (LMCCS) for systematically checking the consistency between Landsat 7 surface reflectance products and MODIS Terra products. High levels of agreements between the two sets of products are supporting evidence that the surface reflectance values in the Landsat products are comparable with those in the MODIS data, while obvious discrepancies between them likely indicate data quality problems with one or both sets of products that warrant further examination. In this approach, object-oriented programming (OOP) principles have been implemented in the system design to support further model extension. The system development has been facilitated using open-sources libraries. This system could be used as a stand-alone system or together with a Landsat processing system like the LEDAP. This paper describes the major considerations in designing and implementing this system, and highlights some of the issues revealed by this system in evaluating preliminary surface reflectance products derived using the GLS 2000 Landsat data set.

\section{Overview of MODIS and Landsat surface reflectance algorithms}

\subsection{MODIS surface reflectance algorithm}

The MODIS atmospheric correction scheme is based on the Second Simulation of a Satellite Signal in the Solar Spectrum Vector Code (6S) radiative transfer code (Vermote et al., 1997b). It calculates surface reflectance by accounting for the effect of gaseous absorption, molecules, and aerosol scattering. Some limitations of the algorithm are the use of a Lambertian model especially at shorter wavelength (e.g., $0.55 \mu \mathrm{m}$ ) (Wang et al., 2010) and the use of the dark target approach for aerosol retrieval that does not produce results over bright targets like deserts (Levy et al., 2007). Detailed descriptions of the MODIS surface reflectance algorithm can be found in many previous publications (Vermote et al., 1997a, 2002; Vermote and Kotchenova, 2008a).

Several MODIS surface reflectance products produced at different spatial resolutions using different temporal aggregation or compositing schemes are available (Justice et al., 2002). The MODIS Terra daily gridded surface reflectance product (MOD09GA) available for download from NASA's Warehouse Inventory Search Tool (WIST, https://wist.echo.nasa.gov/) is used in this study. This product has the Sinusoidal projection and provides reflectance value at the $500 \mathrm{~m}$ spatial resolution for MODIS bands 1-7, as well as observation and geolocation statistics.

\subsection{Landsat surface reflectance algorithm}

The Landsat surface reflectance algorithm is described in Masek et al. (2006) and is based on the MODIS approach (Vermote et al., 2002). It uses the 6S radiative transfer code to 
compute the transmission, intrinsic reflectance, and spherical albedo for relevant atmospheric constituents (Vermote et al., 1997b), and to calculate surface reflectance by compensating for atmospheric scattering and absorption effects on the TOA reflectance. The relevant atmospheric constituents include gases, ozone, water vapor, and aerosols. Ozone concentration was derived from the Total Ozone Mapping Spectrometer (TOMS) aboard the Nimbus-7, Meteor-3, and Earth Probe platforms as well as from NOAA's Television Infrared Observation Satellite Program (TIROS) Operational Vertical Sounder (TOVS) ozone data when TOMS data were not available. Column water vapor was taken from NOAA National Centers for Environmental Prediction (NCEP) reanalysis data (available at http://dss.ucar.edu/datasets/ ds090.0/). Digital topography (1 km GTopo30) and NCEP sea level pressure data were used to adjust Rayleigh scattering to local conditions. Aerosol optical thickness (AOT) was directly derived from the Landsat image using the dark, dense vegetation method of Kaufman et al. (1997).

\section{Considerations for comparing Landsat and MODIS surface reflectance products}

\subsection{Agreement measures}

Since the Landsat 7 and the Terra MODIS follow the same orbit, their equator crossing times differ by only about $30 \mathrm{~min}$ (i.e., equatorial crossing times from 10:00 to 10:15 AM for Landsat 7 and 10:30 for Terra), and each Landsat multispectral band has a MODIS band with a similar bandwidth (Landsat 7 Science Data Users Handbook, 2009) (Table 1), the Landsat reflectance values, when aggregated spatially using the MODIS pixel coverage, should be similar to the MODIS reflectance values for the same location. For a Landsat image acquired at date $(t)$, its reflectance values can be aggregated using the MODIS pixel coverage according to

$C_{t}=\sum\left(L_{t}^{i} \times p_{t}^{i}\right)$,

where $C_{t}$ is an aggregated reflectance value, $i$ is spatial index (location) of Landsat pixels within the concerned MODIS pixel coverage, $L_{t}^{i}$ is surface reflectance of a Landsat pixel, and $p_{t}^{i}$ is area percentage of that pixel in the MODIS pixel coverage. Since Landsat and MODIS surface reflectance values are expected to be very close, their relationships can be modeled using a simple linear regression as follows to examine the agreement between Landsat $\left(C_{t}\right)$ and MODIS surface reflectance $\left(M\left(x_{i}, y_{j}, s, t\right)\right)$ :

$M\left(x_{i}, y_{j}, s, t\right)=a \times C\left(x_{i}, y_{j}, s, t\right)+b$,

here $\left(x_{i}, y_{j}\right)(i, j \in[1, n])$ is a given pixel location for both Landsat and MODIS images. Suppose we have $n$ pairs input of $C\left(x_{i}, y_{j}, s, t\right)$ and $M\left(x_{i}, y_{j}, s, t\right)$ and each pair is acquired on the same date, $s$ and $t$ represent the spectra band and acquisition date for both MODIS and ETM + data, $a$ represents the linear slope, and $b$ represents the offset of linear relationship between MODIS and ETM+ surface reflectance. $a$ and $b$ can be calculated to represent the differences between the surface reflectance pairs using linear regression, and represent the line that has minimum error value from all input data regardless of the correlation and difference between the two input values. In order to evaluate the correlation and differences between MODIS and Landsat data, $R^{2}$ (see Eq. (3)) and root mean square deviation (RMSD) (see Eq. (4)) are introduced into the approach

$R^{2}=1-\frac{\sum_{i, j}\left(M\left(x_{i}, y_{j}, t\right)-C\left(x_{i}, y_{j}, t\right)\right)^{2}}{\sum_{i, j}\left(M\left(x_{i}, y_{j}, t\right)-\bar{M}\right)^{2}}$,
$\operatorname{RMSD}=\sqrt{\frac{\sum_{i, j}\left(M\left(x_{i}, y_{j}, t\right)-C\left(x_{i}, y_{j}, t\right)\right)^{2}}{n}}$.

\subsection{Spatial considerations}

Use of the above agreement measures as indicators of the consistency between Landsat and MODIS reflectance values requires that the ground footprints of the two sets of values match. Matching the footprints of Landsat and MODIS observations, however, can be complicated by several issues, including data coordinate reference system (CRS), residual misregistration errors (Rojas et al., 2002), sensor's point spread function (PSF) (Vermote et al., 1997a; Huang et al., 2002), adjacency effect (Ouaidrari and Vermote, 1999), and view angle effect (Schaaf et al., 2002). These issues need to be addressed properly in order to minimize their impact on the agreement measures calculated using Eqs. (1)-(4).

\subsubsection{Reprojection of MODIS data}

The MODIS data are provided in the Sinusoidal projection, but the Landsat images have the Universal Transverse Mercator (UTM) projection. Because the spatial resolution of the MOD09GA data is $500 \mathrm{~m}$, roughly 16.6 times that of the Landsat data, the reflectance values in the Landsat data need to be aggregated spatially to match the MODIS pixels. In order to match the coverage of each MODIS pixel with correspondent Landsat pixels more accurately, the four corners of each MODIS pixel can be used to draw a geospatial polygon to represent the boundary of that MODIS pixel, which can then be reprojected using the projection of the Landsat data (to be discussed in detail in Section 4.2). Only Landsat pixels located within the boundary of that MODIS pixel should be used to calculate an average reflectance value, which will be compared to the value of that MODIS pixel (see Fig. 1).

\subsubsection{Use of homogeneous regions}

The Landsat-MODIS relationship as described in Eq. (2) likely will degrade over nonhomogeneous areas, because the impact of residual misregistration errors (Rojas et al., 2002), adjacency effect (Ouaidrari and Vermote, 1999), and sensor's PSF is more significant in such areas (Vermote et al., 1997a; Huang et al., 2002). The residual geolocation errors in the GLS Landsat data could be up to $50 \mathrm{~m}(1 \sigma)$ (Tucker et al., 2004), and the $500 \mathrm{~m}$ resolution MOD09GA data geolocation has also been improved to $50 \mathrm{~m}(1 \sigma)$ at nadir (Wolfe et al., 2002). While in Eq. (1) the Landsat pixels are aggregated using a simple spatial average method, the actual MODIS PSF has higher weighting factors at the center of a MODIS pixel and lower weights toward pixel edges, and has non-zero weights for immediately neighboring areas outside the footprint of that pixel (Rojas et al., 2002). In nonhomogeneous areas considerable differences may exist between the values derived using the MODIS PSF and a simple spatial average filter (Huang et al., 2002). The impact of the residual misregistration errors and the sensor's PSF can be minimized using samples selected from homogeneous areas.

Since the MOD09GA data have a geolocation accuracy of less than one MODIS pixel (Wolfe et al., 2002), we use a window with size of $3 \times 3$ MODIS pixels to identify homogeneous regions at the MODIS resolution. Specifically, for each pixel a value range is calculated as the difference between the maximum and the minimum values of the 9 MODIS pixels in the $3 \times 3$ window centered at that MODIS pixel. A MODIS pixel is considered in a homogeneous region if the value range is less than a predefined threshold value. We developed the value range threshold based 


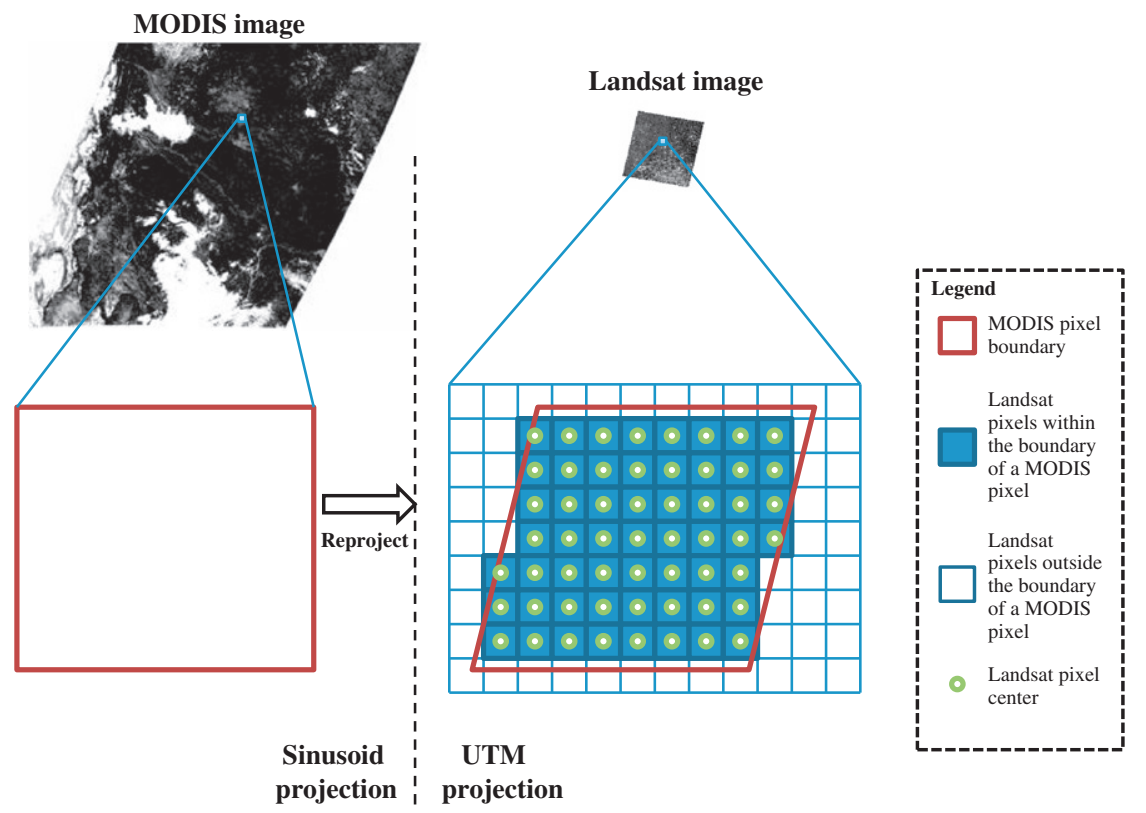

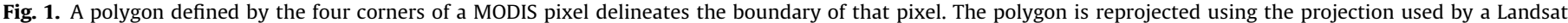
image (i.e., UTM) before it is overlaid on the Landsat image to determine the Landsat pixels that are located within the boundary of that MODIS pixel.

Table 2

Value range threshold values used to determine homogeneous regions at both Landsat and MODIS resolutions.

\begin{tabular}{lll}
\hline MODIS band & Landsat band & Threshold (absolute reflectance value) \\
\hline $\mathbf{3}$ & 1 & 0.03 \\
$\mathbf{4}$ & 2 & 0.03 \\
$\mathbf{1}$ & 3 & 0.03 \\
$\mathbf{2}$ & 4 & 0.06 \\
$\mathbf{6}$ & 5 & 0.03 \\
$\mathbf{7}$ & 7 & 0.03 \\
\hline
\end{tabular}

on our observations at homogeneous Landsat pixels for the 6 Landsat bands (see Table 2). Similarly, the value range of all Landsat pixels located within a MODIS pixel coverage is used to determine whether the MODIS pixel is also homogeneous at the Landsat resolution. Only samples that are homogeneous at both the Landsat and the MODIS resolutions are selected. These samples are then divided into 10 equal percentiles using a cumulative histogram, and $20 \%$ of the samples in each percentile are used to calculate the agreement measures described in Section 3.1

\subsubsection{View angle control}

In mid- to high-latitude regions, MODIS can produce more than one observation per day in certain areas (Wolfe et al., 2002). In those areas the pixels in the MOD09GA product do not necessarily have the same view zenith angle as the Landsat image acquired on the same day. To avoid the potential impact of different view zenith angles on the reflectance values, only MODIS pixels having view zenith angles within the view zenith angle range of the Landsat (i.e., $\pm 7.5^{\circ}$ from nadir) are used in the comparison.

\subsection{Temporal considerations}

Because the MODIS on the Terra platform is only about $30 \mathrm{~min}$ later than the Landsat 7, the approach assumes that the atmospheric condition does not change much in $30 \mathrm{~min}$; the two
Table 3

The three bits used to indicate cloud state and shadow presence in the MODIS $1 \mathrm{~km}$ resolution QA band (Vermote and Vermeulen, 1999).

\begin{tabular}{llll}
\hline Bit no. & Parameter name & Bit combination & State \\
\hline $\mathbf{0 - 1}$ & Cloud state & 00 & Clear \\
& & 01 & Cloudy \\
& & 10 & Mixed \\
& & 11 & Not set \\
$\mathbf{2}$ & Cloud shadow & 1 & Yes \\
& & 0 & No \\
\hline
\end{tabular}

instruments should see roughly the same atmospheric condition when they pass the same location each day (Vermote et al., 2002). When clouds are present in their view, however, the two instruments may find those clouds and their shadows at different locations, because clouds can move a lot in $30 \mathrm{~min}$. To minimize the impact due to cloud movement on the comparison results, we exclude both cloud and shadow pixels from the comparison. In the MODIS data, cloud and shadow are identified using the internal cloud and shadow masks from the MODIS QA band, which is a 16 bits band with $1 \mathrm{~km}$ spatial resolution. Two of the 16 bits are used to represent cloud state; one bit indicates cloud shadow status (Vermote and Kotchenova, 2008b) (see Table 3). Since minimal cloud cover was one of the considerations in selecting the GLS images (Tucker et al., 2004), the LMCCS tool does not check the cloud cover in the Landsat images.

\subsection{Key processing steps}

Based on the above considerations, four major steps are needed in order to perform a Landsat-MODIS comparison for each spectral band:

1. Initial sample selection. For each Landsat image and its simultaneously acquired MODIS image, the comparison is performed based on samples. Each sample is a surface reflectance value pair collected from both Landsat and MODIS images at the same coordinate. The MODIS value is retrieved from the 
MODIS pixel at the coordinate, and the Landsat value is retrieved by aggregating the Landsat pixels within the MODIS pixel coverage (see next entry). The sample coordinates could be selected either randomly or with the use of a systematic sampling method within the overlaid region of the two images. In the system developed in this study, the sample coordinates are selected systematically by picking one out of 3 MODIS pixels in both the horizon and vertical directions.

2. Spatial aggregation of Landsat data. As discussed above, in order to match a MODIS pixel with the Landsat pixels, a polygon is generated to represent the MODIS pixel coverage under MODIS Sinusoidal projection, which is reprojected using the UTM projection used by the Landsat image. The Landsat pixels located within the reprojected polygon are used to calculate an average surface reflectance value that will be compared with the MODIS reflectance value at that sample coordinate.

3. Sample filtering. The initial samples are filtered to exclude nonhomogeneous pixels, pixels contaminated by cloud and shadow, MODIS pixels with view zenith different than the Landsat, etc. The samples used in the final comparison are selected to represent the spectral range of the concerned images.
4. Calculation of agreement measures. The samples retained after the filtering process in step 3 are used to calculate the agreement measures according to Eqs. (3) and (4).

\section{Implementation of the LMCCS}

\subsection{System overview}

The LMCCS consists of two modules, i.e., Geospatial Image Metadata Administration (GIMA) and Surface Reflectance Consistency Checking (SRCC) module (Fig. 2). The GIMA module ingests metadata from collected MOD09GA images to facilitate quickly identifying simultaneously acquired MODIS image for the Landsat-MODIS comparison. The SRCC module implements the comparison discussed in Section 3. Open-source geospatial libraries, e.g., GeoTools (http://www.geotools.org), PROJ.4 (http:// trac.osgeo.org/proj/), and JFreeChart (http://www.jfree.org/jfree chart), are used in system development. To add flexibility, the system was designed to run as a stand-alone package or as a component of other Landsat data processing systems.

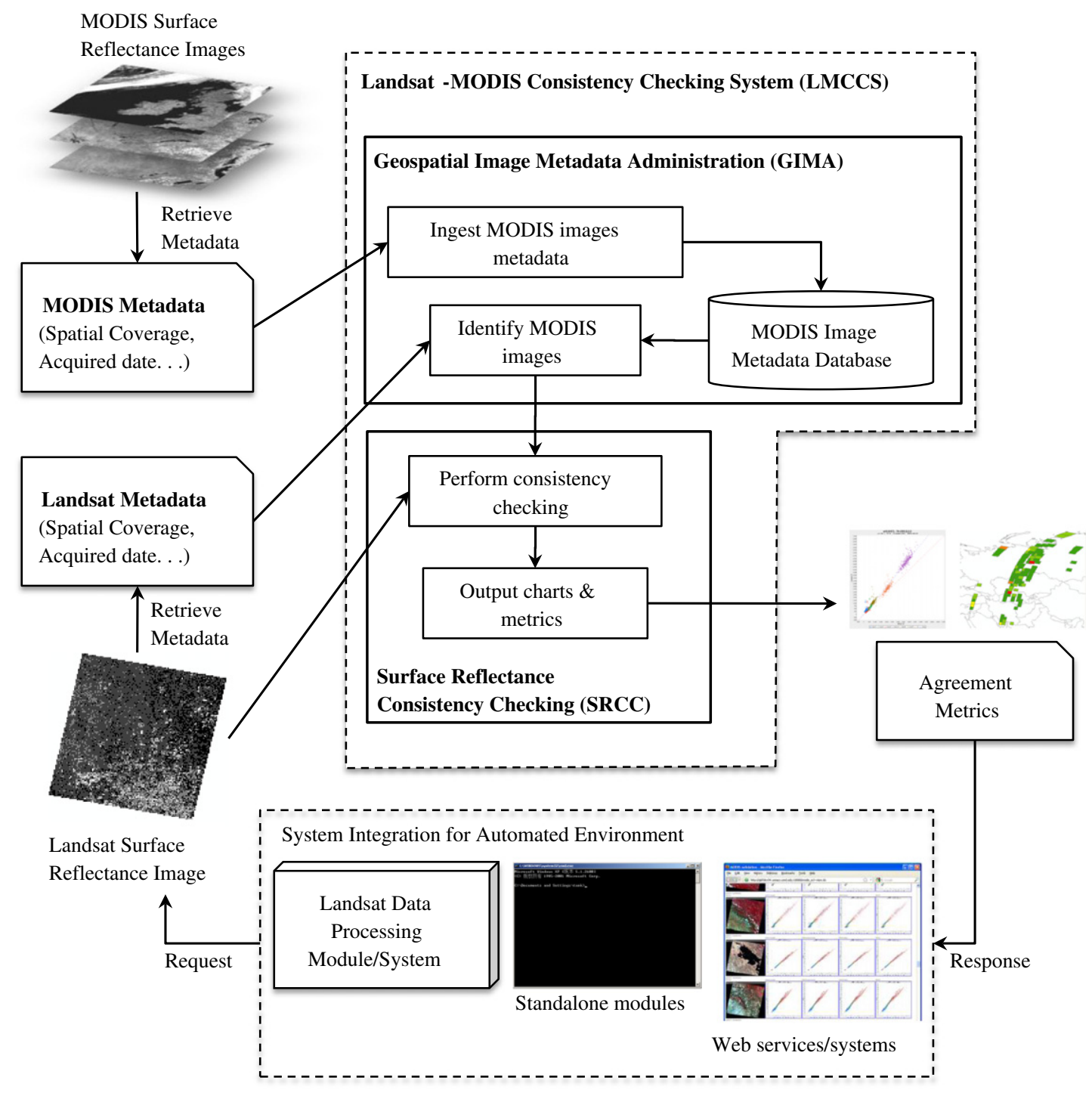

Fig. 2. A flowchart of the Landsat-MODIS Consistency Checking System (LMCCS). 


\subsection{Geospatial Image Metadata Administration (GIMA)}

Each GLS epoch includes about 9000 Landsat images, and roughly the same amount of MODIS images need to be collected to perform the Landsat-MODIS comparison. For each Landsat image, identifying its simultaneously acquired MOD09GA images requires spatial and temporary matching analysis within the available MOD09GA images (see Section 4.2.2), and it would be inefficient to perform the analysis without database support, especially when processing thousands of Landsat images. In addition, it would be very challenging to manually track the image acquisition process and manage such a large amount of images. To address this problem, we built a database to manage the acquired MODIS images and provide an efficient way for identifying MODIS images.

\subsubsection{Geospatial powered MODIS Image Metadata Database}

The metadata for each MOD09GA image includes nonspatial components (e.g., acquisition date, image storage path, etc.), and spatial components (e.g., geospatial coverage). In order to support the storage and operations of geospatial metadata items, the MODIS Image Metadata Database is built based on the PostGIS package to leverage its geospatial data storage and operation capabilities. PostGIS extends the PostgreSQL database and supports geospatial data types and functions defined in OGC Simple Features Specification for SQL (Egenhofer, 1990). In addition to the columns for those nonspatial metadata items, a geospatial polygon-type column is added to store the spatial coverage of each image and Generalized Search Tree (GiST) geospatial indexing is created on the column to enhance performance of geospatial query. Unfortunately, the Sinusoidal projection used by the MODIS data is not supported by the current version of PostGIS. To address this problem, we added this projection to PostGIS using PROJ.4 and Well-Known Text (WKT) definition syntax:

PROJ.4: + proj $=$ sinu + lon $\_0=0+x \_0=0+y \_0=0+a=6371007$. $181+b=6371007.181+$ units $=m$

WKT: PROJCS["MODIS_Sinusoidal",GEOGCS["GCS_Sphere",["D_Sphere",SPHEROID["Sphere",6371007.181,0.0]],

PRIMEM["Greenwich",0.0],UNIT["De-

gree",0.0174532925199433]],

PROJECTION["Sinusoidal"],PARAMETER["False_Easting",0.0],

\section{PARAMETER["False_Northing",0.0],PARAMETER["Central_ Meridian",0.0],UNIT["Meter",1.0]]}

The GIMA allows users to retrieve metadata from the MOD09GA images in the HDF-EOS format (Wei et al., 2007), and ingest these retrieved metadata items into the MODIS Image Metadata Database. Because MODIS data are provided using a tiling system that does not change over time, and the spatial coverage of each tile predefined and known, the spatial coverage polygon of each MODIS image is derived based on its path/row number in the MODIS tiling system (see Fig. 3A).

\subsubsection{Identification of simultaneously acquired MODIS images}

Identifying simultaneously acquired MODIS images is complicated by handling the different projections and tiling systems of MODIS and Landsat data. The MOD09GA data are distributed by NASA WIST in MODIS Sinusoidal projection and MODIS tiling system (see Fig. 3A). Landsat $\mathrm{TM} / \mathrm{ETM}+$ data are distributed in UTM projection and USGS Worldwide Reference System-2 (WRS-2) tiling system (see Fig. 3B).

For each Landsat image, the MODIS images that were acquired on the same date as the Landsat image and encompass or intersect with that image need to be identified. This can be achieved by querying the geospatial MODIS Image Metadata Database. One complication is that the MODIS images have the Sinusoidal projection while the Landsat images have the UTM projection. The spatial coverage of each Landsat image needs be converted to the MODIS Sinusoidal projection before it can be overlaid on the MODIS images.

The mathematic construction of the MODIS Sinusoidal projection at coordinates $(x, y)$ is defined as

$x=R\left(\lambda-\lambda_{0}\right) \cos \varphi \quad y=R \varphi$,

where $R$ is the radius of the Earth defined as a sphere $(6,371,007.181 \mathrm{~m}$ for MODIS Sinusoidal), $\lambda(\lambda \in[-\pi, \pi])$ the geographic longitude in radian, $\lambda_{0}$ the longitude of the central meridian in radian, and $\varphi(\varphi \in[-\pi / 2, \pi / 2])$ the geographic latitude in radian (Seong et al., 2002).

Mathematical transformation of UTM coordinates to coordinates in the MODIS Sinusoidal projection is achieved using PROJ.4. After converting the coordinates of four corners of a Landsat image into coordinates in the MODIS Sinusoidal projection, the

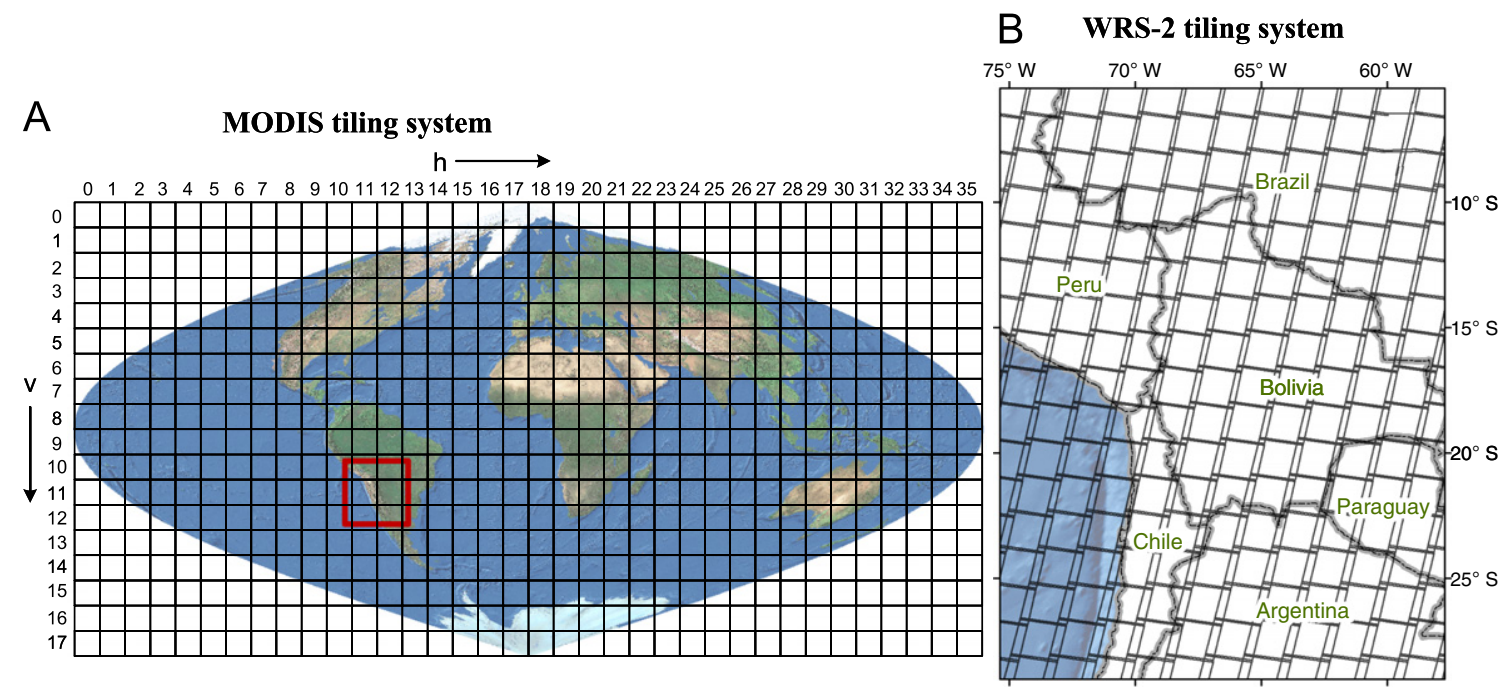

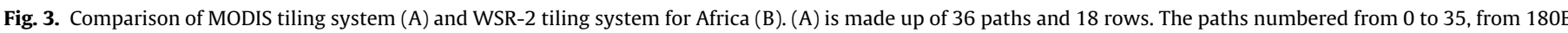

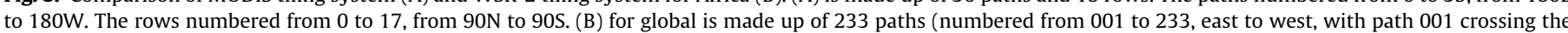

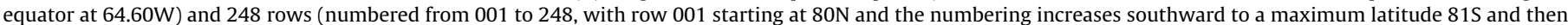
turns northward) 


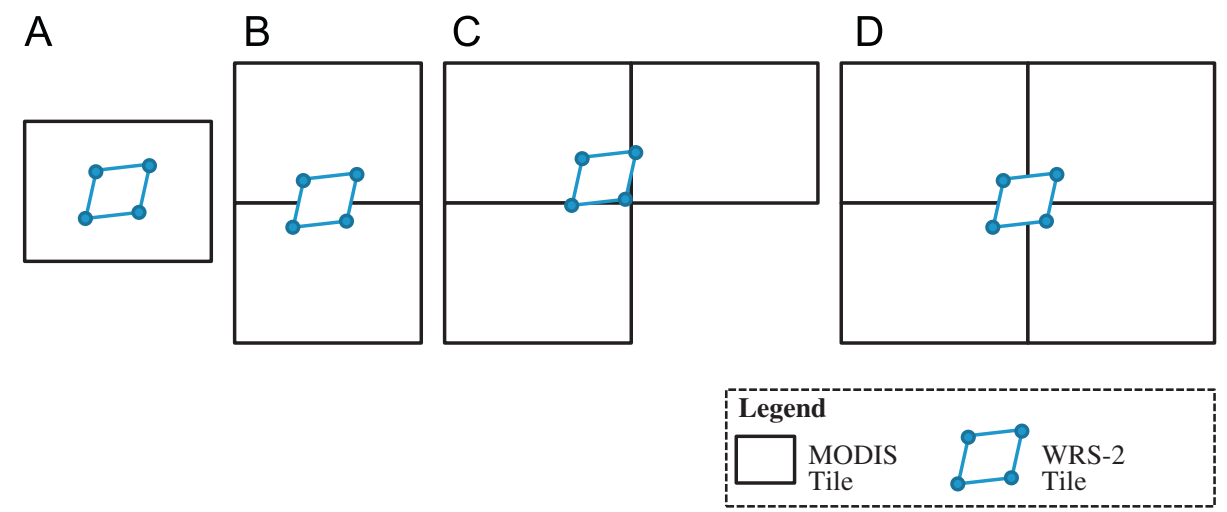

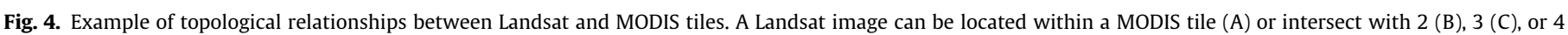
(D) MODIS tiles.

spatial coverage polygon of the Landsat image in the MODIS Sinusoidal projection can be reconstructed by connecting the four corners in a clockwise or anticlockwise order. When a Landsat image crosses the longitude line at $180 \mathrm{E} / 180 \mathrm{~W}$, however, a spatial coverage polygon constructed this way will be wrong. To solve this problem, the area covered by the Landsat image is split into two parts along the $180 \mathrm{E} / 180 \mathrm{~W}$ longitudinal line. This way neither part crosses this longitude line, and the spatial coverage polygons of both parts in the MODIS Sinusoidal projection can be reconstructed following the procedure described earlier, which are eventually combined into a multipolygon geometry.

After reprojecting the Landsat spatial coverage polygon using the MODIS Sinusoidal projection, the MODIS images needed to cover the target Landsat image can be identified based on their topologic relation to the Landsat image. Depending on the geographic location, a Landsat image could be located within a MODIS tile, or interest with two to four Landsat tiles (see Fig. 4).

\subsection{Surface Reflectance Consistency Checking (SRCC)}

The Landsat-MODIS comparison process discussed in Section 3 has been implemented in the SRCC module following OOP principles. OOP can facilitate the design and maintenance of model implementation especially when the system involves various data sources and subprocesses, or keeps growing by adding new algorithm components (Wolfsthal, 1994). In this case, OOP can benefit the system by organizing the algorithms in the comparison process and extending sample filtering and matrices algorithms in future.

In OOP, the structure of object is defined by class. By inheriting a class (derived class) from another class (base class), the derived class reuses structure definition from the predefined base class (Thirunarayan, 1999). In addition to deriving attributes and functions from its base class, the derived class is also allowed to append more entities or even override the existing entities. Because the derived class contains everything that its base class has, it can act like its base class and be used to replace its base class without notifying the program units dependent on the base class. As such, inheritance can facilitate module extension by developing a derived class. Class could be designed only for extending purposes, and it is termed as abstract class opposed to concrete class. The abstract class has virtual functions which are required to be implemented by derived classes.

The SRCC module consists of two class groups, i.e., framework classes and algorithm classes (see Fig. 5). The framework classes implement the key Landsat-MODIS comparison steps (see Section 3.4) and basic elements associated with the comparison. Two abstract classes (i.e., SampleFiltering and IndictorCal class) are defined in the framework group to establish a way for adding algorithms classes into the comparison. The algorithm classes implement algorithms for sample filtering and metrics calculation. Each algorithm class implements a particular algorithm and inherits one of the two abstract classes described earlier.

\subsubsection{Basic framework classes}

An object of Sample class represents one of the samples collected over the simultaneously acquired Landsat and MODIS images. In addition to the sample coordinate, the object includes a surface reflectance value pair and attributes related to the sample (e.g., MODIS zenith angle, MODIS cloud state, etc.). The surface reflectance value pair is collected from the MODIS and Landsat images at the sample coordinate, and the valid surface reflectance value range is from -100 to 16,000 (0.0001 scale factor) (Vermote and Kotchenova, 2008b). Samples with surface reflectance values out of the range are likely falling into the invalid image regions (e.g., image filling region, ETM + scan line corrector (SLC) strips (Landsat 7 Science Data Users Handbook, 2009)), and are removed from the sample collection. The MODIS zenith value is retrieved from the $1 \mathrm{~km}$ resolution sensor zenith band (MODIS_Grid_1 km_2D SensorZenith_1). The MODIS cloud state is retrieved from the $1 \mathrm{~km}$ QA band (see Table 3 ).

An object of the GeoRaster class encapsulates a geospatial image and associated operations. Its attributes include the geospatial coverage (extent), row and column number (size), and data blocks (tiles). Because loading large satellite images may consume lots of computer memory, data block is introduced to the system to allow loading a small portion rather than the whole image. Therefore, two functions are provided by the class to support reading specified pixel (readPixel) and data block (readTile).

The Validation class implements the individual band comparison process (see Section 3.4) in its validationBand function. In addition, the validationImage function performs comparison on the whole Landsat image by summarizing the comparison result for each band.

\subsubsection{Sample filtering classes}

The SampleFiltering class is an abstract class that defines the common attributes and functions needed for sample filtering algorithm classes. Each algorithm class is required to inherit the SampleFiltering class and implement its algorithm in the filter function. The algorithm class receives input samples from the samples attribute before calculation, and returns processed samples after calculation. 


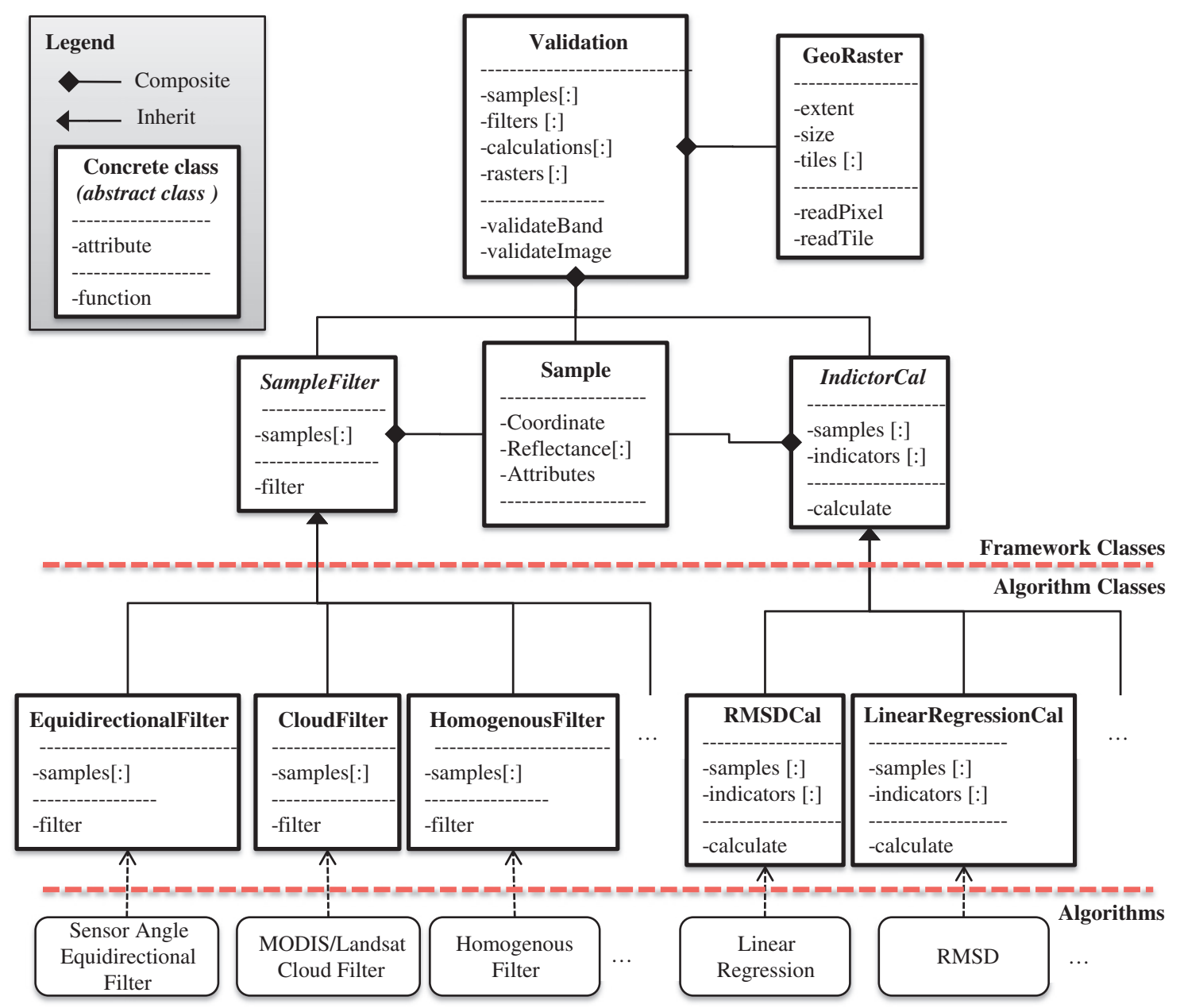

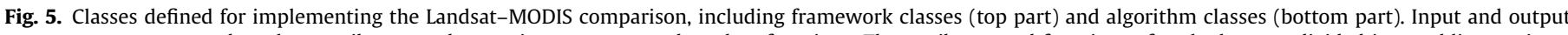

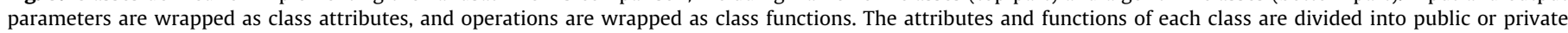
groups according to their usage scope. Only the public scope attributes and functions are illustrated in the figure.

Three algorithm classes were created:

1. The CloudFiltering class detects cloud samples based on their MODIS cloud states. Samples with state other than "Clear" will be excluded from the comparison.

2. The EquidirectionalFilter class excludes samples with MODIS zenith angle out of the Landsat zenith angle range $\left( \pm 7.5^{\circ}\right)$.

3 . The HomogeneousFilter class detects and excludes the heterogeneous observations of MODIS and Landsat following the rules discussed in Section 3.2.2.

\subsubsection{Metrics calculation classes}

The IndictorCal abstract class defines the common attributes and function for calculating the agreement metrics. Each algorithm class has to inherit the IndictorCal class and implement its algorithm in calculation function. The algorithm class receives collected samples through samples attribute before calculation, and returns agreement metrics through the indictor attributes after calculation. Two algorithm classes were created to implement the linear regression (LinearRegressionCal class) and RMSD calculation (RMSDCal class), respectively.

\subsection{Outputs from Landsat-MODIS comparison}

Outputs from the Landsat-MODIS comparison include agreement metrics, scatter plots, and a shapefile showing the distribution of the agreement metrics for all Landsat images for a particular area. Agreement metrics include those discussed in Section 3.1 and are calculated for individual band (Landsat bands from 1 to 5 , and 7) as well as by pooling all 6 bands together (see Table 4 ). Note that algorithm classes are extendable and more metrics can be calculated when new algorithms are added to the system.

Scatter plots provide graphic views of the agreement metrics. A scatter plot is produced for each individual Landsat band, and an overall plot is generated by pooling all 6 spectral bands together (see Fig. 6). For continental to global scale applications that involve large quantities of Landsat images, a map showing the spatial distribution of the agreement metrics would allow quick identification of images having low agreement values. To meet such needs, the LMCCS also outputs the agreement metrics in shapefile format, which can be loaded and visualized as maps (see Fig. 9).

\subsection{System integration in an automated environment}

The LMCCS is developed using Java programming languages. Java has been widely supported by open communities. Implementing the system using Java can be benefited from millions of third part libraries and tools, especially the open geospatial libraries. Java is one of the OS independent programming languages, so the system can be used on any operation systems that support Java Virtual Machine (JVM), including UNIX/Linux 
Table 4

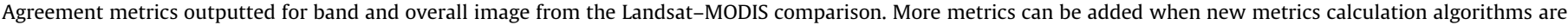
introduced into the system.

\begin{tabular}{|c|c|c|c|}
\hline Algorithms & $\begin{array}{l}\text { Agreement } \\
\text { metrics }\end{array}$ & $\begin{array}{l}\text { Theoretical } \\
\text { ranges }\end{array}$ & Descriptions \\
\hline $\begin{array}{l}\text { Linear regression } \\
\text { calculation }\end{array}$ & $\begin{array}{l}\text { Slope (a) } \\
\text { Offset (b) } \\
R^{2}\end{array}$ & $\begin{array}{l}{[-\infty, \infty]} \\
{[-\infty, \infty]} \\
{[0,1]}\end{array}$ & $\begin{array}{l}\text { The slope and offset indicate the linear regression trend between Landsat and MODIS. For close trend, the slope is } \\
\text { expected to be close to } 1 \text {, and offset is expected to be close } 0 \text {. } \\
\text { The metric indicates the correlation between Landsat and MODIS. For good correlation, } R^{2} \text { is expected to be close to } 1 \text {. }\end{array}$ \\
\hline RMSD calculation & RMSD & {$[0, \infty]$} & $\begin{array}{l}\text { The metric indicates the difference between Landsat and MODIS. The value is expected to be near } 0 \text { for little } \\
\text { difference. }\end{array}$ \\
\hline
\end{tabular}

A

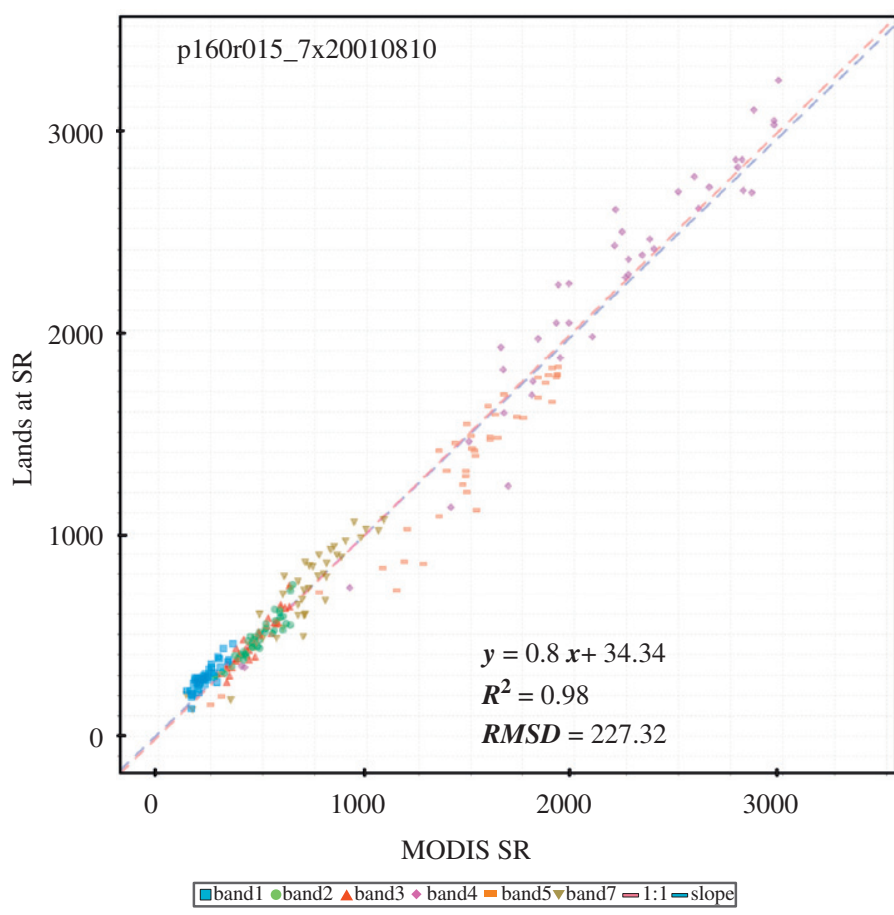

B

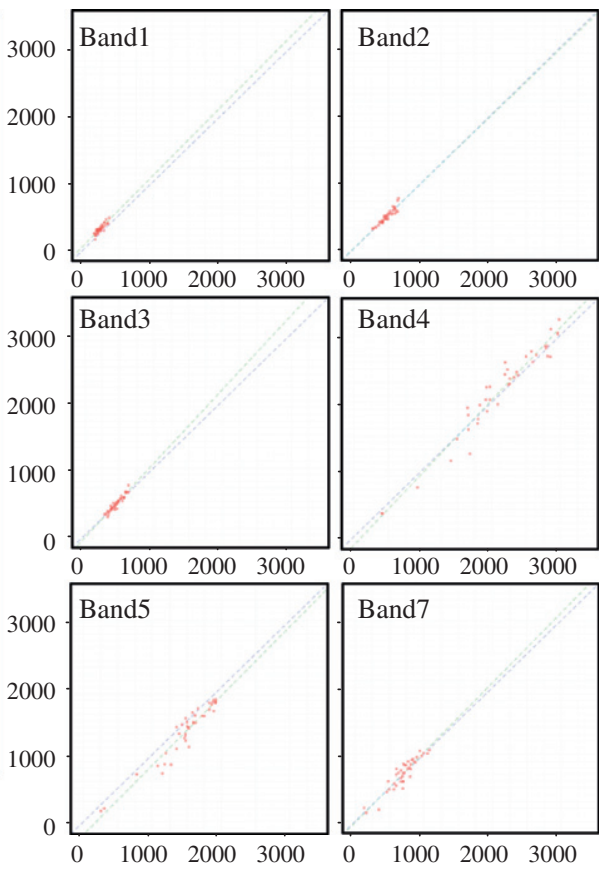

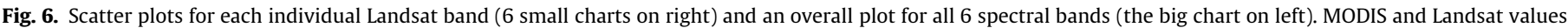

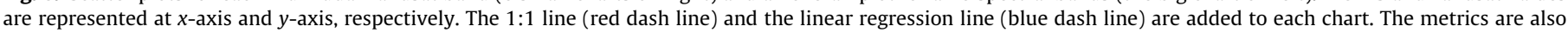

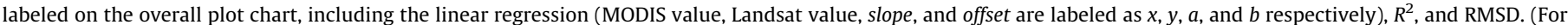
interpretation of the references to color in this figure legend, the reader is referred to the web version of this article.)

servers and personal computers. In order to facilitate automated use of the system, the system provides utility functions which can be executed as command lines. Thus, both users and other systems, such as LEDAP, will be able to use the system through those commands. Benefiting from the available Java-based Web server containers, e.g., Apache Tomcat (http://tomcat.apache.org/), GlassFish (https://glassfish.dev.java.net/), we believe that the system can be shared online with little modifications in future.

\section{Utilization of the LMCCS}

The overall goal of the LMCCS is to provide an efficient mechanism for verifying that surface reflectance products derived using Landsat images are consistent with those derived using MODIS data. High levels of consistency between the two products are indicators that both products are likely reliable and the reflectance values are comparable, and inconsistencies between Landsat and MODIS products as revealed by this system likely indicate quality problems with the Landsat products that need further investigation. Preliminary surface reflectance products derived from GLS 2000 epoch Landsat data have been used to evaluate the approach, and revealed problems in the products that were traced to incorrect version of the LEDAPS surface reflectance code and erroneous inputs.

\subsection{Incorrect version of the LEDAPS surface reflectance code}

An earlier version of the LEDAPS code obtained from NASA GSFC was used to produce a surface reflectance product using the GLS ETM+ image. The LMCCS revealed that the Landsat reflectance values were quite different from MODIS values in many places. Fig. 7A shows the comparison results generated by the LMCCS for a cloud free image acquired over southern Turkey (WRS-2 path 174/row 34) on June 22, 2000. An investigation revealed that the module for retrieving calibration parameters from Landsat metadata files was designed for early versions of those files. After replacing that module with a new version designed to handle the metadata file format of the GLS data set, 
A

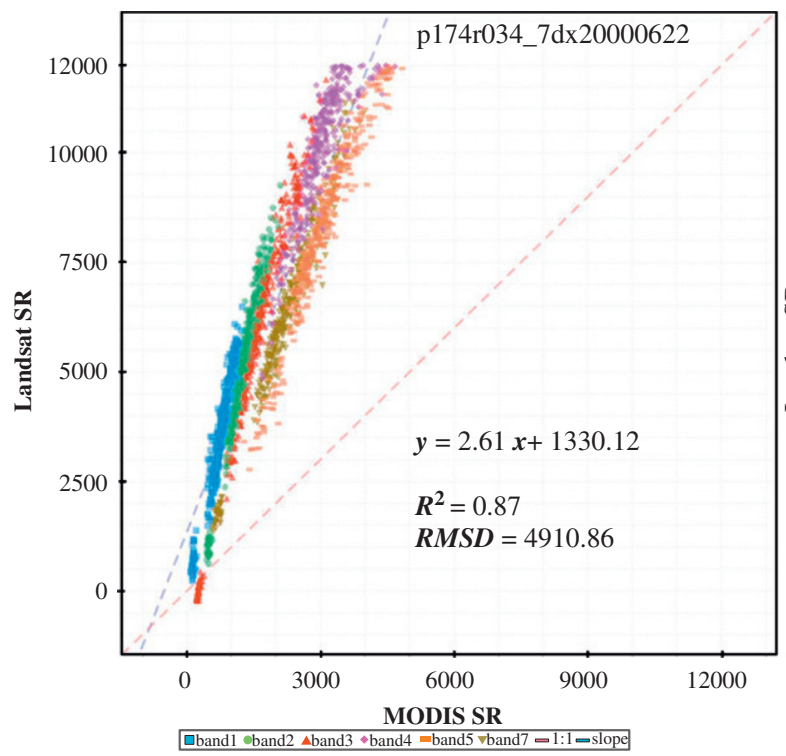

B

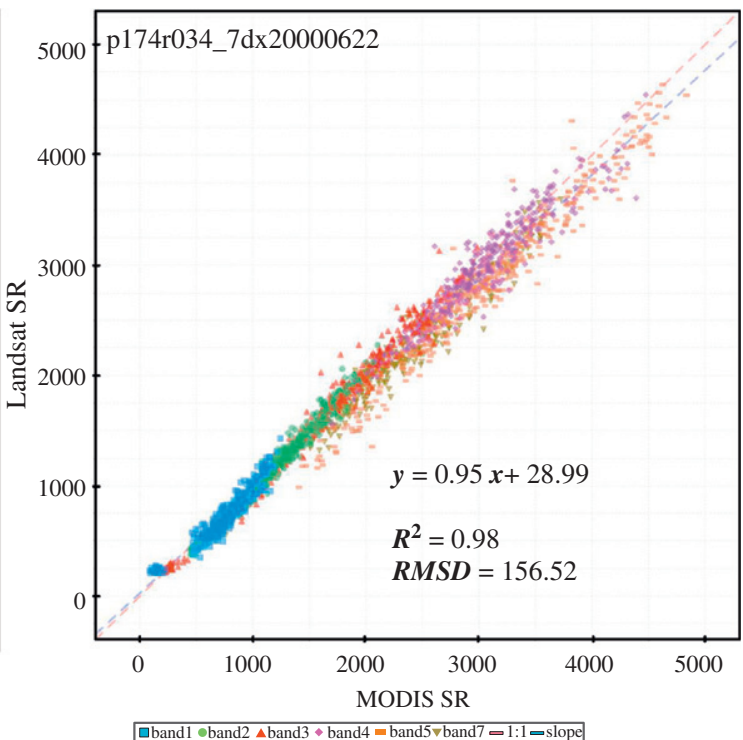

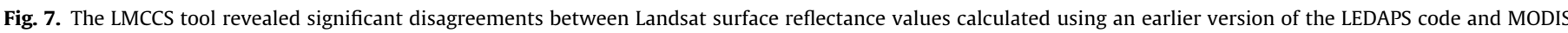

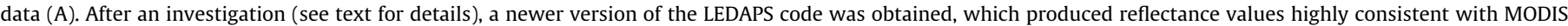
data (B). In the example shown here, the Landsat 7 image was acquired on June 22, 2000, over southern Turkey (WRS-2 path 174/row 34).

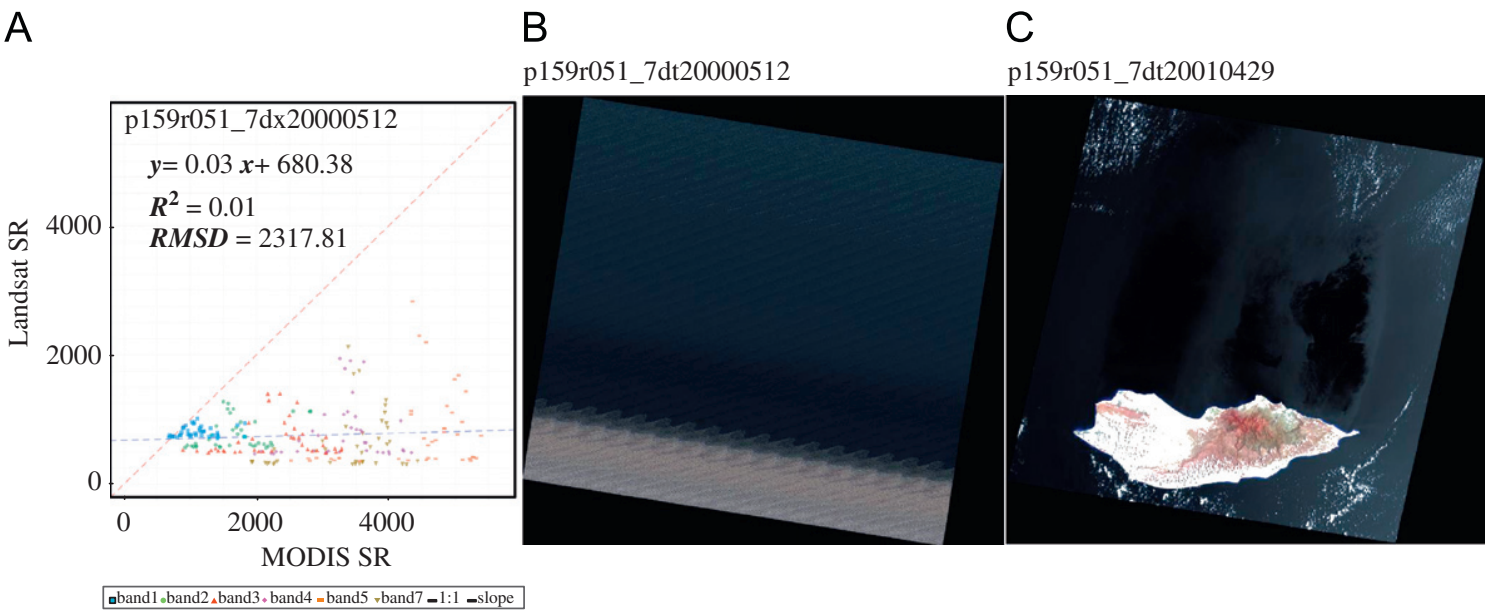

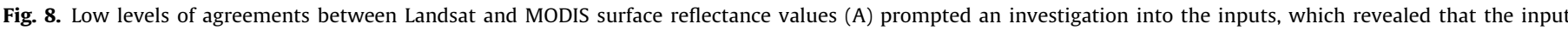

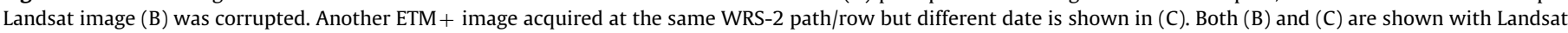

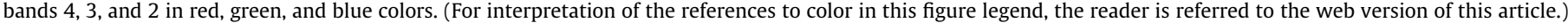

the LEDAPS code produced surface reflectance values highly consistent with the MODIS values (Fig. 7B).

\subsection{Erroneous GLS images}

The GLS data set consists of nearly 10,000 Landsat images produced using automated or semiautomated approaches, providing a near complete coverage of all land areas of the Earth (Tucker et al., 2004; Gutman et al., 2008). It is not clear whether each image has been checked to identify images that may have obvious quality problems. Since the LMCCS is designed for checking every Landsat image, it provides a mechanism for screening all GLS images to identify images that have obvious quality issues. Fig. 8A gives the Landsat-MODIS scatter plot generated by the LMCCS for a GLS 2000 acquired on May 12, 2000 , in Socotra, Yemen (WRS-2 path 159/row 51), which shows that there is essentially no correlation between Landsat and MODIS reflectance values. A visual check of the input image revealed that it was a corrupted image (Fig. 8B) compared to a normal image acquired at the same location (Fig. 8C). To our knowledge, this problematic image has never been identified after the GLS and its predecessor the GeoCover became available.

\subsection{MODIS surface reflectance calibration issue}

The LMCCS identified inconsistencies on band 7 of a Landsat surface reflectance image in the Sahara desert area. An investigation revealed problematic values in its simultaneously acquired MODIS image. The issue has been reported to the MODIS team and confirmed to be a calibration error on band 7 of the MODIS image, which was acquired during the sensor's early operation stage. Fig. 9 shows the Landsat image (Fig. 9A) acquired on April 20, 2000, in Libya (WRS-2 path 181/row 43) and its simultaneously acquired MODIS image (Fig. 9B). 
A

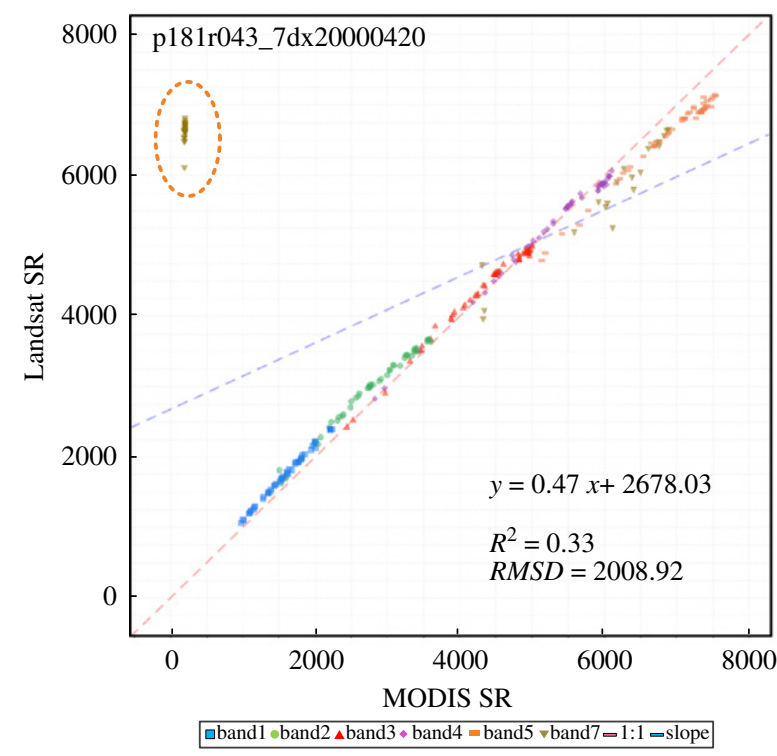

B

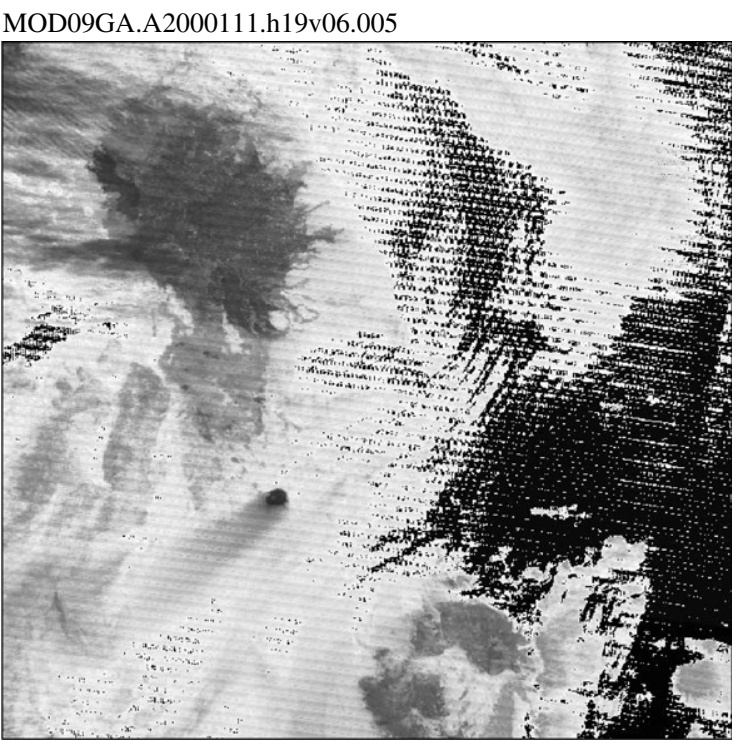

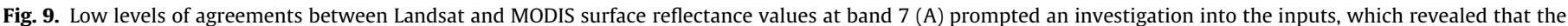

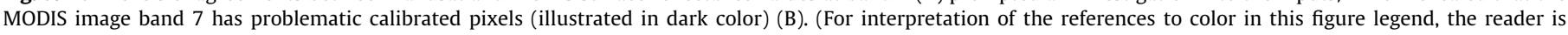
referred to the web version of this article.)

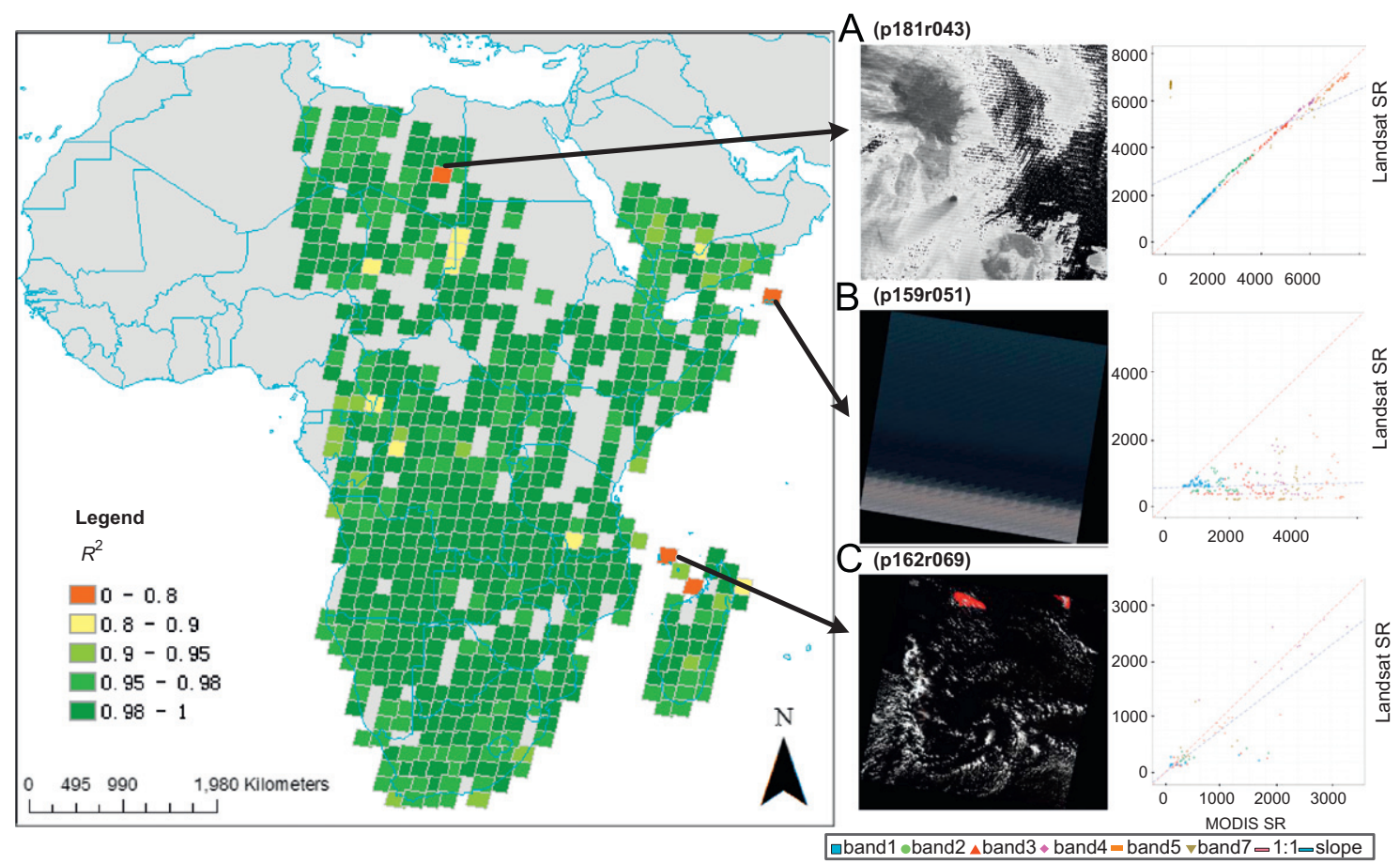

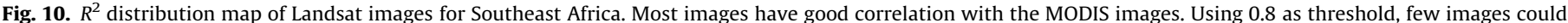

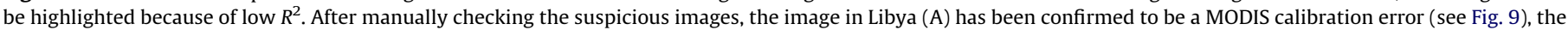
image on the northeast corner (B) has been confirmed to be a corrupted image (see Fig. 8), and the images near Madagascar Island (C) are caused by residual cloud.

\subsection{Consistency check from regional to global scales}

To improve the efficiency of checking large quantities of Landsat images needed to cover a large area, the LMCCS also outputs the agreement measures into a shapefile, which can be used to create maps showing the spatial distribution of those agreement measures. By visually inspecting these maps, areas where Landsat and MODIS reflectance values are inconsistent can be identified quickly. Fig. 10 shows a map of the $R^{2}$ value generated from the Landsat-MODIS scatter plots for 723 GLS images covering most areas in eastern Africa. It shows that of the 723 images evaluated here, only four of them had $R^{2}$ values less than 0.8. Further investigations on the four images revealed that one of them had a problem with the original input image (see Section 5.2), another one caused by problematic calibration of MODIS (see Section 5.3), and the other two had very small 
portions of land area. These two images have lots of clouds over water, many of which may not have been flagged properly and contributed to the low correlations between the Landsat and MODIS data.

\section{Discussion and conclusions}

Advances in developing automated atmospheric correction algorithms coupled with available computing and storage capacities have made it feasible to produce large quantities of surface reflectance products using Landsat images (Masek et al., 2006). During the process of converting raw satellite radiometry to surface reflectance, however, errors could be introduced from many potential sources, including incorrect input parameters, corrupted input images, bugs in the atmospheric correction algorithm or use of an incorrect version of the algorithm, and operator errors (Roy et al., 2002). To rule out the impact of such potential error sources, it is necessary to have a sanity check on the surface reflectance values derived from each Landsat image.

Because MODIS surface reflectance products have been validated comprehensively and are available globally since 2000, they can be used as a reference to validate the radiometric quality of surface reflectance products derived from essentially all Landsat images acquired during the MODIS era. Such a quality assessment approach is especially valid for Landsat 7 images because the MODIS on the Terra platform and the Landsat 7 share the same orbit and are only half an hour apart, and each of the 6 Landsat spectral bands overlaps with a MODIS band. In general, good agreements between MODIS and Landsat surface reflectance values can be considered indicators of the reliability of the Landsat products, while disagreements may suggest potential quality problems with the surface reflectance products that need to be further investigated. However, a number of factors can lead to low agreement between Landsat and MODIS reflectance values even when both products are perfectly valid, including pixel misalignment due to improper handling of pixel and image geometry, fine scale spectral variations coupled with uneven weightings of sensor's point spread function, and significant changes in atmospheric conditions that may occur between the overpass of the Landsat 7 and the Terra MODIS.

The LMCCS is designed to perform automatic comparison of Landsat and MODIS surface reflectance data while eliminating or minimizing the impact of the factors described above on the derived agreement metrics. In this tool, MODIS and Landsat pixels are aligned properly using a widely used reprojection tool and by tracking the geometry of pixels in both data types accurately. The impact of fine scale spectral variations and sensor's point spread function is minimized by only using samples from homogeneous regions in calculating agreement metrics. For Landsat images having minimal cloud cover, which in theory should be case for the GLS images, the implemented cloud screening mechanism that only considers clouds in the MODIS data can effectively reduce the impact of changes in cloud location and/or radiometry that may have occurred between the overpasses of the Landsat 7 and the Terra MODIS (Fig. 11). For more general use of the LMCCS regardless of cloud cover in the Landsat images, the cloud screening mechanism should consider clouds in both the Landsat and the MODIS data.

To improve the robustness of the LMCCS in an automated environment, a number of issues have been considered in developing the LMCCS. The geospatial MODIS Image Metadata Database allows quick identification of simultaneously acquired MODIS images needed to cover any Landsat image. MODIS data gaps resulting from various practical reasons have been identified properly, and the database can be updated as more MODIS data are made available. Many reprojection tools have difficulties in handling images that encompass the $180 \mathrm{E} / 180 \mathrm{~W}$ longitudinal line. This situation has been handled properly in the LMCCS.

To maximize its portability, the LMCCS is developed using Java and open-source libraries. It does not require any commercial software and can be deployed on any platform that supports JVM. In 2008, NASA and USGS implemented a free Landsat Data Distribution Policy that provides level 1 terrain corrected data for the entire U.S. Landsat archive, and the needs of quality assessment are increasing while more Landsat surface reflectance are expected to be produced from the free Landsat data. The Java-based LMCCS has great potential to be modified to be an online system, providing operational quality assessment ability to more users through the Internet. OOP principles are followed in order to make this tool more flexible for future expansion, including use of new filters and sampling schemes, adding new agreement metrics, and adaption for use with other Landsat class instruments such as the China-Brazil Earth Resources Satellite (CBERS), the Linear Imaging and Self-Scanning sensor (LISS-III) and Advanced Wide Field Sensor (AWiFS) onboard the Indian
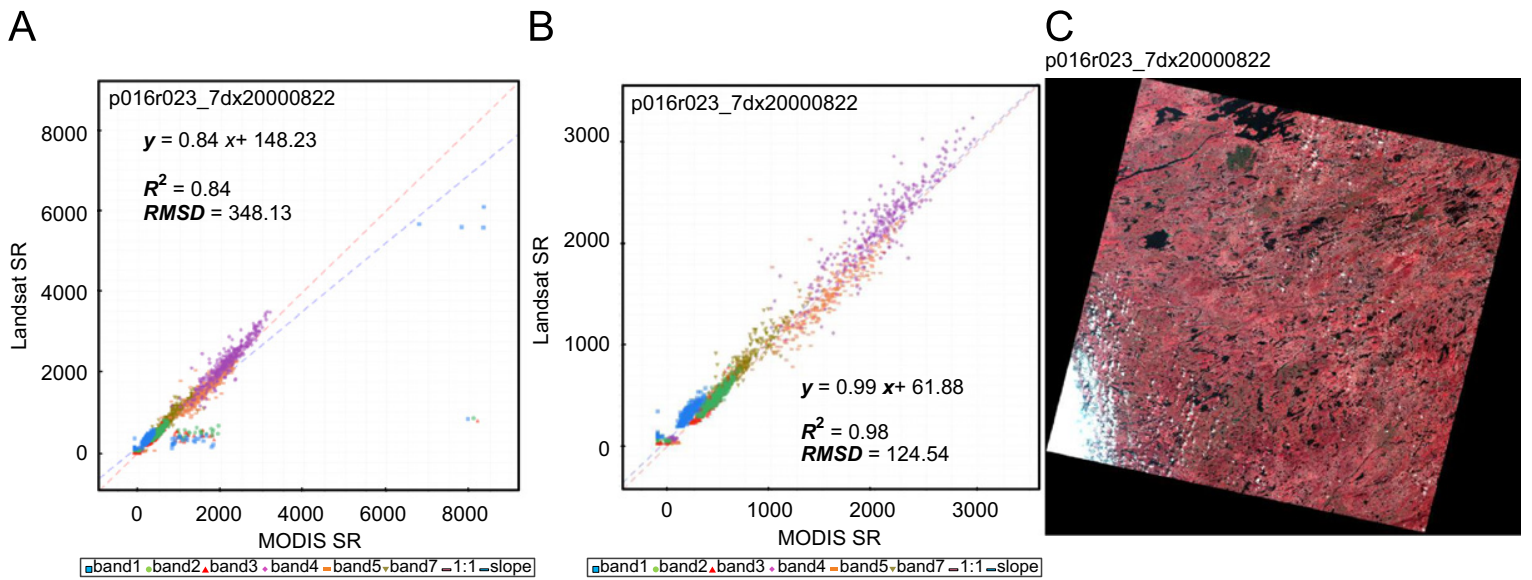

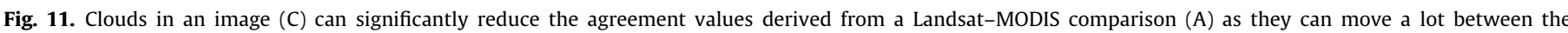

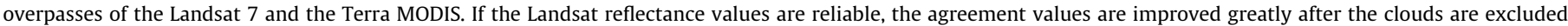

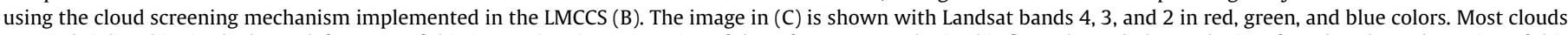

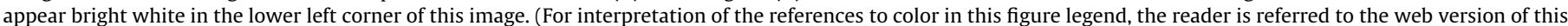
article.) 
Remote Sensing Satellites (IRS), and the Advanced Spaceborne Thermal Emission and Reflection Radiometer (ASTER) onboard NASA's Earth Observing System (EOS) Terra spacecraft. This approach also has the potential to be adapted for quality assessment of surface reflectance produced from next generation Landsat sensors, the LDCM. Due to orbital differences, for some of these instruments, including the Landsat 5, the Terra MODIS may not provide a daily image that is acquired on the same day as the image to be assessed and has illumination and viewing geometry similar to that image (Landsat 7 Science Data Users Handbook, 2009). In such cases, the MODIS Nadir BRDF-Adjusted Reflectance (Schaaf et al., 2002) product may be the best alternative that can be used in the place of the MOD09GA data.

\section{Acknowledgments}

Funding support for this study was provided by the following NASA programs: making Earth System Data Records for Use in Research Environments (NNH06ZDA001N-MEASURES), Land Cover and Land Use Change (NNH07ZDA001N-LCLUC), and Earth System Science Research Using Data and Products from Terra, Aqua, and Acrimsat Satellites (NNH06ZDA001N-EOS). The MODIS daily products used in this study were obtained through Greg Ederer and Robert Wolfe. The GLS datasets were sent to GLCF by Rachel Headley. Joseph O. Sexton, Raghuram Narasimhan, and other colleagues and collaborators of the Global Forest Cover Change (GFCC) Project provided valuable inputs for improving this manuscript and the method described here. We also thank Prof. Jiulin Sun for his support on this work.

\section{References}

Egenhofer, M.J., 1990. Interaction with geographic information systems via spatial queries. Journal of Visual Languages and Computing 1 (4), 389-413. doi:10.1016/S1045-926X(05)80022-9.

Fang, H., Liang, S., Chen, M., Walthall, C., Daughtry, C., 2004. Statistical comparison of MISR, ETM + and MODIS land surface reflectance and albedo products of the BARC land validation core site, USA. International Journal of Remote Sensing 25 (2), 409-422. doi:10.1080/0143116031000101666.

Fang, H., Liang, S., Kim, H.Y., Townshend, J.R., Schaaf, C.L., Strahler, A.H., Dickinson, R.E., 2007. Developing a spatially continuous $1 \mathrm{~km}$ surface albedo data set over North America from Terra MODIS products. Journal of Geophysical Research 112 (D20206), 0-20. doi:10.1029/2006JD008377.

Goward, S., Arvldson, T., Williams, D., Faundeen, J., Irons, J., Franks, S., 2006. Historical record of Landsat global coverage: mission operations, NSLRSDA and international cooperator stations. Photogrammetric Engineering and Remote Sensing 72 (10), 1155-1169.

Goward, S.N., Williams, D.L., 1997. Landsat and Earth systems science: development of terrestrial monitoring. Photogrammetric Engineering and Remote Sensing 63 (7), 887-900.

Gutman, B.G., Byrnes, R., Masek, J., Covington, S., 2008. Towards monitoring landcover and land-use changes at a global scale: the Global Land Survey 2005 Photogrammetric Engineering and Remote Sensing 74 (1), 6-10.

Huang, C., Goward, S.N., Schleeweis, K., Thomas, N., Masek, J.G., Zhu, Z., 2009a. Dynamics of national forests assessed using the Landsat record: case studies in eastern United States. Remote Sensing of Environment 113 (7), 1430-1442.

Huang, C., Kim, S., Song, K., Townshend, J.R., Davis, P., Altstatt, A., Rodas, O., Yanosky, A., Clay, R., Tucker, C.J., 2009b. Assessment of Paraguay's forest cover change using Landsat observations. Global and Planetary Change 67 (1-2) 1-12. doi:10.1016/j.gloplacha.2008.12.009.

Huang, C., Townshend, J.R., Liang, S., Kalluri, S.N., DeFries, R.S., 2002. Impact of sensor's point spread function on land cover characterization: assessment and deconvolution. Remote Sensing of Environment 80 (2), 203-212.

Huete, A., Didan, K., Miura, T., Rodriguez, E.P., Gao, X., Ferreira, L.G., 2002 Overview of the radiometric and biophysical performance of the MODIS vegetation indices. Remote Sensing of Environment 83 (1-2), 195-213. doi:10.1016/S0034-4257(02)00096-2.

Irons, J.R., Masek, J.G., 2006. Requirements for a Landsat data continuity mission. Photogrammetric Engineering and Remote Sensing 72 (10), 1102-1108.

Justice, C.O., Townshend, J.R., Vermote, E.F., Masuoka, E., Wolfe, R.E., Saleous, N., Roy, D.P., Morisette, J.T., 2002. An overview of MODIS land data processing and product status. Remote Sensing of Environment 83 (1-2), 3-15. doi:10.1016/ S0034-4257(02)00084-6.

Kaufman, Y.J., Wald, A.E., Remer, L.A., Gao, B.C., Li, R.R., Flynn, L., 1997. The MODIS $2.1-\mu \mathrm{m}$ channel-correlation with visible reflectance for use in remote sensing of aerosol. IEEE Transactions on Geoscience and Remote Sensing 35 (5), 1286-1298.

Kotchenova, S.Y., Vermote, E.F., 2007. Validation of a vector version of the $6 \mathrm{~S}$ radiative transfer code for atmospheric correction of satellite data. Part II. Homogeneous Lambertian and anisotropic surfaces. Applied Optics 46 (20), 4455-4464. doi:10.1364/AO.46.004455.

Landsat 7 Science Data Users Handbook, 2009. Landsat 7 Science Data Users Handbook. Landsat Project Science Office. NASA Goddard Space Flight Center, Greenbelt Maryland. 〈http://landsathandbook.gsfc.nasa.gov/handbook.html 〉.

Levy, R.C., Remer, L.A., Dubovik, O., 2007. Global aerosol optical properties and application to Moderate Resolution Imaging Spectroradiometer aerosol retrieval over land. Journal of Geophysical Research 112 (D13), 1-15 <http://www. agu.org/pubs/crossref/2007/2006JD007815.shtml $>$.

Liang, S., Fang, H., Chen, M., Shuey, C.J., Walthall, C., Daughtry, C., Morisette, J. Schaaf, C., Strahler, A., 2002. Validating MODIS land surface reflectance and albedo products: methods and preliminary results. Remote Sensing of Environment 83 (1-2), 149-162. doi:10.1016/S0034-4257(02)00092-5.

Liang, S., Zheng, T., Liu, R., Fang, H., Tsay, S.C., Running, S., 2006. Estimation of incident photosynthetically active radiation from Moderate Resolution Imaging Spectrometer data. Journal of Geophysical Research 111 (D15208).

Liang, S., Zheng, T., Wang, D., Wang, K., Liu, R., Tsay, S., Running, S., Townshend, J., 2007. Mapping high-resolution incident photosynthetically active radiation over land from polar-orbiting and geostationary satellite data. Weather 73 (10), 1085-1089.

Masek, J.G., Vermote, E.F., Saleous, N.E., Wolfe, R., Hall, F.G., Huemmrich, K.F., Gao, F., Kutler, J., Lim, T.K., 2006. A Landsat surface reflectance dataset for North America, 1990-2000. IEEE Geoscience and Remote Sensing Letters 3 (1), 68-72. doi:10.1109/LGRS.2005.857030.

Myneni, R.B., Nemani, R.R., Running, S.W., 1997. Estimation of global leaf area index and absorbed par using radiative transfer models. IEEE Geoscience and Remote Sensing 35 (6), 1380-1393.

Ouaidrari, H., Vermote, E.F., 1999. Operational atmospheric correction of Landsat TM data. Remote Sensing of Environment 70 (1), 4-15. doi:10.1016/S00344257(99)00054-1.

Rojas, F., Schowengerdt, R.A., Biggar, S.F., 2002. Early results on the characterization of the terra MODIS spatial response. Remote Sensing of Environment 83 (1-2), 50-61.

Roy, D.P., Borak, J.S., Devadiga, S., Wolfe, R.E., Zheng, M., Descloitres, J., 2010. Webenabled Landsat data (WELD): Landsat ETM + composited mosaics of the conterminous United States. Remote Sensing of Environment 114 (1), 35-49 Available at: $\langle$ http://dx.doi.org/10.1016/j.rse.2009.08.011 $\rangle$.

Roy, D.P., et al., 2002. The MODIS land product quality assessment approach. Remote Sensing of Environment 83 (1-2), 62-76<http://dx.doi.org/10.1016/ S0034-4257(02)00087-1>.

Schaaf, C.B., Gao, F., Strahler, A.H., Lucht, W., Li, X., Tsang, T., Strugnell, N.C., Zhang, X., Jin, Y., Muller, J.P., Lewis, P., Barnsley, M., Hobson, P., Disney, M., Roberts, G., Dunderdale, M., Doll, C., D’Entremont, R.P., Hu, B., Liang, S., Privette, J.L., Roy, K., 2002. First operational BRDF, albedo nadir reflectance products from MODIS. Remote Sensing of Environment 83 (1-2), 135-148. doi:10.1016/ S0034-4257(02)00091-3.

Seong, J.C., Mulcahy, K.A., Usery, E.L., 2002. The Sinusoidal projection: a new importance in relation to global image data. Professional Geographer 54 (2), 218-225.

Song, C., Woodcock, C.E., Seto, K.C., Lenney, M.P., Macomber, S.A., 2001. Classification and change detection using Landsat TM data when and how to correct atmospheric effects? Remote Sensing of Environment 75 (2), 230-244. doi:10.1016/S0034-4257(00)00169-3.

Thirunarayan, K., 1999. Simulating multiple inheritance and generics in Java. Computer Languages 25 (4), 189-210. doi:10.1016/S0096-0551(00)00005-9.

Townshend, J., Justice, C., Li, W., Gurney, C., Mcmanus, J., 1991. Global land cover classification by remote sensing: present capabilities and future possibilities. Remote Sensing of Environment 35 (2-3), 243-255. doi:10.1016/00344257(91)90016-Y.

Tucker, C.J., Grant, D.M., Dykstra, J.D., 2004. NASA's global orthorectified Landsat data set. Photogrammetric Engineering and Remote Sensing 70 (3), 313-322.

Vermote, E.F., El Saleous, N., Justice, C.O., Kaufman, Y.J., Privette, J.L., Remer, L., Roger, J.C., Tanré, D., 1997a. Atmospheric correction of visible to middleinfrared EOS-MODIS data over land surfaces: background, operational algorithm and validation. Journal of Geophysical Research 102 (D14), 17131-17141. doi:10.1029/97JD00201.

Vermote, E.F., Kotchenova, S.Y., 2008a. Atmospheric correction for the monitoring of land surfaces. Journal of Geophysical Research 113 (D23), D23S90. doi:10.1029/2007JD009662.

Vermote, E.F., Kotchenova, S.Y., 2008b. MOD09 (Surface Reflectance) User's Guide. $\langle$ http://modis-sr.Itdri.org/products/MOD09_UserGuide_v1_2.pdf 〉.

Vermote, E.F., Nazmi, S.Z., Privette, J.L., 2006. Surface Reflectance Earth System Data Record/Climate Data Record White Paper. Greenbelt, MD. 〈http://landportal. gsfc.nasa.gov/Documents/ESDR/Surface_Reflectance_Vermote_whitepaper.pdf $\rangle$.

Vermote, E.F., Saleous, N.Z., Justice, C.O., 2002. Atmospheric correction of MODIS data in the visible to middle infrared: first results. Remote Sensing of Environment 83 (1-2), 97-111. doi:10.1016/S0034-4257(02)00089-5.

Vermote, E.F., Tanre, D., Deuze, J.L., Herman, M., Morcette, J.J., 1997b. Second simulation of the satellite signal in the solar spectrum, 6S: an overview. IEEE Transactions on Geoscience and Remote Sensing 35 (3), 675-686. doi:10.1109/36.581987. 
Vermote, E.F., Vermeulen, A., 1999. Atmospheric correction algorithm: spectral reflectances (MOD09). Algorithm Theoretical Background Document. Available online at $\langle$ http://modarch.gsfc.nasa.gov/MODIS/ATBD/atbd_mod08.pdf $\rangle$.

Wang, Y., Lyapustin, A.I., Privette, J.L., Cook, R.B., SanthanaVannan, S.K., Vermote, E.F., Schaaf, C.L., 2010. Assessment of biases in MODIS surface reflectance due to Lambertian approximation. Remote Sensing of Environment 114 (11), 2791-2801〈http://dx.doi.org/10.1016/j.rse.2010.06.013〉.

Wang, Y., Lyapustin, A.I., Privette, J.L., Morisette, J.T., Holben, B., 2009. Atmospheric correction at AERONET locations: a new science and validation data set. IEEE Transactions on Geoscience and Remote Sensing 47 (8), 2450-2466.
Wei, Y., Di, L., Zhao, B., Liao, G., Chen, A., 2007. Transformation of HDF-EOS metadata from the ECS model to ISO 19115-based XML. Computers and Geosciences 33 (2), 238-247. doi:10.1016/j.cageo.2006.06.006.

Wolfe, R.E., Nishihama, M., Fleig, A.J., Kuyper, J.A., Roy, D.P., Storey, J.C., Patt, F.S. 2002. Achieving sub-pixel geolocation accuracy in support of MODIS land science. Remote Sensing of Environment 83 (1-2), 31-49.

Wolfsthal, Y., 1994. The road to effective software development. IEEE Communications Magazine 32 (4), 84-87. doi:10.1109/35.275340. 